Boise State University

ScholarWorks

$4-6-2021$

\title{
The American Kestrel (Falco sparverius) Genoscape: Implications for Monitoring, Management, and Subspecies Boundaries
}

\author{
Michaela Brinkmeyer \\ Boise State University \\ Julie A. Heath \\ Boise State University
}

\section{Publication Information \\ Ruegg, Kristen C.; Brinkmeyer, Michaela; Bossu, Christen M.; Bay, Rachel A.; Anderson, Eric C.; Boal, Clint W.; . . . and Heath, Julie A. (2021). "The American Kestrel (Falco sparverius) Genoscape: Implications for Monitoring, Management, and Subspecies Boundaries". Ornithology, 138(2), ukaa051. https://doi.org/ 10.1093/auk/ukaa051}

This is a pre-copyedited, author-produced PDF of an article accepted for publication in Ornithology following peer review. The version of record

Ruegg, K.C., Brinkmeyer, M., Bossu, C.M., Bay, R.A., Anderson, E.C., Boal, C., . . \& Heath, J.A. (2021). The American Kestrel (Falco sparverius) Genoscape: Implications for Monitoring, Management, and Subspecies Boundaries. Ornithology, 138(2), ukaa051.

is available online at https://doi.org/10.1093/auk/ukaa051 
This is an author-produced, peer-reviewed version of this article. The final, definitive version of this document can be found online at $A u k$ : Ornithological Advances, published by Oxford University Press on behalf of the American Ornithological Society. Copyright restrictions may apply. https://doi.org/10.1093/auk/ukaa051. The content of this document may vary from the final published version.

Title: The American Kestrel (Falco sparverius) Genoscape: Implications for Monitoring, Management, and Subspecies Boundaries

Kristen C. Ruegg ${ }^{1,2^{*}}$, Michaela Brinkmeyer ${ }^{3 *}$, Christen M. Bossu ${ }^{1,2}$, Rachael A. Bay ${ }^{2,4}$, Eric C. Anderson ${ }^{5}$, Clint W. Boal ${ }^{6}$, Russell D. Dawso ${ }^{7}$, Amber Eschenbauch ${ }^{8}$, Christopher JW McClure ${ }^{9}$, Karl E. Miller ${ }^{10}$, Lance Morrow ${ }^{11}$, Jill Morrow ${ }^{11}$, M. David Oleyar ${ }^{12}$, Bill Ralph ${ }^{13}$, Sarah Schulwitz ${ }^{9}$, Ted Swem ${ }^{14}$, Jean-Francois Therrien ${ }^{15}$, Thomas B. Smith ${ }^{2,15}$, Julie A. Heath ${ }^{3}$

*These authors contributed equally.

Author Mailing Addresses:

${ }^{1}$ Biology Department, Colorado State University, 251 W. Pitkin St, Fort Collins, CO 80521

${ }^{2}$ Center for Tropical Research, Institute of the Environment and Sustainability, University of California, 619 Charles E Young Drive East, Los Angeles, CA 90095, USA

${ }^{3}$ Department of Biological Sciences and Raptor Research Center, Boise State University, 1910 University Dr., Boise, ID 83725, USA.

${ }^{4}$ Department of Evolution and Ecology, University of California Davis, Davis, CA 95616

${ }^{5}$ Fisheries Ecology Division, Southwest Fisheries Science Center, National Marine Fisheries Service, 110 McAllister Way, Santa Cruz, CA 95060

${ }^{6}$ US Geological Survey, Texas Cooperative Fish and Wildlife Research Unit, Texas Tech University, Lubbock, TX 79409

${ }^{7}$ Ecosystem Science and Management Program, University of Northern British Columbia, 3333

University Way, Prince George, BC V2N 4Z9, Canada

${ }^{8}$ Central Wisconsin Kestrel Research, 10115 Yellow Brick Road, Amherst WI 5440, USA.

${ }^{9}$ The Peregrine Fund, 5668 West Flying Hawk Lane, Boise, ID 83709 USA.

${ }^{10}$ Fish and Wildlife Research Institute, Florida Fish and Wildlife Conservation Commission, 1105 SW

Williston Rd., Gainesville, FL 32601, USA

${ }^{11}$ Shenandoah Valley Raptor Study Area, Timberville, VA 22853, USA.

${ }^{12}$ HawkWatch International, 2240 South 900 East, Salt Lake City, UT, 84106, USA.

${ }^{13}$ Yosemite Area Audubon Society, 41932 Bessie Jacobs Rd., Raymond, CA 93653, USA.

${ }^{14}$ U.S. Fish and Wildlife Service, $10112^{\text {th }}$ Avenue, Fairbanks, AK 99701, USA.

${ }^{15}$ Hawk Mountain Sanctuary, 410 Summer Valley Road, Orwigsburg, PA, USA.

${ }^{16}$ Department of Ecology and Evolutionary Biology, University of California, Los Angeles, CA 90095, USA.

Corresponding author: Kristen Ruegg

Department of Biology

Colorado State University

Fort Collins, CO 80521

Kristen.Ruegg@colostate.edu

Running Head: Migrant Conservation Prioritization

Key Words: Genoscape, Conservation Unit, Migratory Bird 
This is an author-produced, peer-reviewed version of this article. The final, definitive version of this document can be found online at Auk: Ornithological Advances, published by Oxford University Press on behalf of the American Ornithological Society. Copyright restrictions may apply. https://doi.org/10.1093/auk/ukaa051. The content of this document may vary from the final published version.

\section{ACKNOWLEDGMENTS}

KCR, JAH, MDO, SS, CJWM, TBS and MB conceived of the idea design and experiment.

$\mathrm{KCR}, \mathrm{MB}, \mathrm{CMB}, \mathrm{RB}$, and ECA collected the genomic data and conducted the bioinformatic and population genetic analyses. $\mathrm{KCR}, \mathrm{MB}, \mathrm{JAH}$, and $\mathrm{CMB}$ wrote the manuscript with contributions from all co-authors. MB, CWB, RDD, AE, CJWM, KEM, LM, JM, MDO, BR, SS, TS, JFT, and JAH contributed blood samples for the genome-wide genetic analysis. We thank Joel Pagel and Little Gap Raptor Research for contributing samples to the genomic analysis, Anjolene Hunt for coordinating sample collection for the Kestrel Genoscape Project, the many generous supporters who contributed to the American Kestrel genoscape via a crowd-sourcing campaign, and the many citizen scientists who contributed feather samples for genetic analysis through the Peregrine Fund's American Kestrel Partnership as well as other channels. This work was made possible by a generous gift from J. Ellis, a California Energy Commission grant to K. Ruegg and T. Smith (EPC-15-043), a National Geographic grant to K. Ruegg (WW-202R-17), a donation from First Solar Incorporated, the Boise State Raptor Research Center, the Raptor Research Foundation's Dean Amadon Grant, and a grant to JAH from the Strategic Environmental Research and Development Program (RC-2702). Funding for the sample collection was provided by Natural Sciences and Engineering Research Council of Canada, Canada Foundation for Innovation, British Columbia Knowledge Development Fund, and University of Northern British Columbia. We thank the DNA Technologies and Expression Analysis Cores at the UC Davis Genome Center (supported by NIH Shared Instrumentation Grant 1S10OD010786-01) for their assistance with the Next-Generation Sequencing. 
1 ABSTRACT: Identifying population genetic structure is useful for inferring

2 evolutionary process and comparing the resulting structure with subspecies boundaries

3 can aid in species management. The American Kestrel (Falco sparverius) is a

4 widespread and highly diverse species with 17 total subspecies, only two of which are

5 found north of United States/Mexico border (F. s. paulus is restricted to southeastern

6 United States, while $F$. s. sparverius breeds across the remainder of the United States and

7 Canadian distribution). In many parts of their US and Canadian range, American

8 Kestrels have been declining, but it has been difficult to interpret demographic trends

9 without a clearer understanding of gene flow among populations. Here we sequence the

10 first American Kestrel genome and scan the genome of 197 individuals from 12 sampling

11 locations across the US and Canada in order to identify population structure. To validate

12 signatures of population structure and fill in sampling gaps across the US and Canada

13 range, we screened 192 outlier loci in an additional 376 samples from 34 sampling

14 locations. Overall, our analyses support the existence of 5 genetically distinct

15 populations of American Kestrels—Eastern, Western, Texas, Florida, and Alaska.

16 Interestingly, we found that while our genome-wide genetic data support the existence of

17 previously described subspecies boundaries in the US and Canada, genetic differences

18 across the sampled range correlate more with putative migratory phenotypes (resident,

19 long-distance, and short-distance migrants) rather than a priori described subspecies

20 boundaries per se. Based on our results, we suggest the resulting five genetically distinct

21 populations serve as the foundation for American Kestrel conservation and management

22 in the face of future threats. 


\section{INTRODUCTION}

24 An important application of population genetics is the identification of genetically

25 distinct populations within species that can be used to guide conservation and

26 management efforts. Depending on the context, such groups are often referred to as

27 subspecies, management units (MUs), evolutionary significant units (ESUs),

28 conservation units, or genetically distinct populations (Moritz 1994, Allendorf and

29 Luikart 2007, Funk et al. 2007). Population genetic structure below the species level has

30 frequently been used to delineate units for conservation and management (Moritz 1994;

31 Allendorf \& Luikart 2007; Funk et al. 2007), but other factors including behavior and

32 morphological variations are also important, particularly in species for which genetic data

33 are absent or lacking in resolution (Mayr 1982, Waples et al. 2007). In highly mobile

34 species it has historically been difficult to identify subspecies that correlate with

35 genetically distinct populations because gene flow often homogenizes the diversifying

36 effects of local adaptation and drift (Waples 1998, Willoughby et al. 2017, Medina et al.

37 2018, Doyle et al. 2018). As a result, identifying genetically distinct populations in

38 migratory animals, such as migratory birds, remains a challenge (Larson et al. 2014, Zink

39 2014, Freer et al. 2015, Mura-Jornet et al. 2018).

41 Traditionally, genetic studies focused on identifying genetically distinct populations

42 relied on a limited number of molecular markers (e.g., microsatellites, mitochondrial (mt)

43 DNA sequences, and allozymes) to make inferences about population genetic structure

44 (Ryman et al. 2006, Morin et al. 2009, Rowe et al. 2011, Mura-Jornet et al. 2018).

45 However, recent advances in sequencing technology have made it possible to screen tens 
46 of thousands to millions of genetic markers and reveal patterns of population structure

47 that may have previously gone undetected (Rowe et al. 2011). For many species, greatly

48 increasing the number of loci included in population genetic analyses has improved the

49 precision of population genetic parameters (Egger et al. 2017), increased the resolution of

50 detectable population genetic structure (Ruegg et al. 2014, Benestan et al. 2015, Jahner et

51 al. 2016), and provided opportunities for fine scale investigations of genetically distinct

52 populations and their relationship to subspecies boundaries (Larson et al. 2014,

53 Fredrickson et al. 2015, Bussche et al. 2017, Mura-Jornet et al. 2018). In migratory birds,

54 Ruegg et al. (2014) coined the term genoscapes to refer to maps of genetic variation

55 across geographic space, but the relationship among genetically distinct populations

56 within a genoscape and previously defined subspecies boundaries has yet to be explored.

57 Here we use Next Generation Sequencing (NGS) technology to create a genoscape for

58 the American Kestrel, assess its relationship to current subspecies boundaries, and

59 provide a framework for conservation and management of this and other highly mobile

60 species with a high capacity for dispersal.

62 The American Kestrel is a widely distributed species that breeds throughout North and

63 South America (Smallwood and Bird 2002) and has upwards of 17 recognized subspecies

64 (Ferguson-Lees and Christie 2006). American Kestrels show highly variable migration

65 strategies across their range, including individuals that migrate long distances, short

66 distances, or do not migrate, and populations that are completely migratory, partially

67 migratory, or non-migratory (Layne 1982, Bird and Palmer 1988, Henny and Brady 1994,

68 Smallwood and Bird 2002). Here we focus on two American Kestrel subspecies found 
69 north of the Mexico / United states border, the non-migratory subspecies (F. s. paulus)

70 found breeding in the southeastern United States and the widespread subspecies (F. $s$.

71 sparverius) found throughout the remainder the United States and Canada (Hoffman and

72 Collopy 1988, Smallwood 1990). In general, it is thought that populations of $F$. $s$.

73 sparverius follow a pattern of leap-frog migration, where migratory distance decreases on

74 a latitudinal gradient, with birds in the northernmost part of the breeding range migrating

75 the farthest and birds in the southernmost part of the range remaining year-round

76 residents (Heath et al. 2012). In addition, there is growing evidence that American

77 Kestrel populations are declining (Bird 2009, Farmer and Smith 2009, Smallwood et al.

78 2009, Hinnebusch et al. 2010), but estimates of demographic trends differ regionally

79 (McClure et al. 2017). One hypothesis to explain regional variation in demographic

80 trends is that genetically distinct populations with different migratory strategies are

81 exposed to different stressors across the annual cycle. As a result, identifying genetically

82 distinct populations in American Kestrels and how they correspond with previously

83 defined subspecies will improve our ability to interpret recent demographic trends and

84 appropriately focus conservation actions.

86 Previous American Kestrel genetic research using five microsatellite loci and one

87 mitochondrial DNA marker identified no strong signal of population genetic structure

88 across the U.S. range, with only subtle differences in allele frequencies between the two

89 recognized subspecies (Miller et al. 2012). Here we employ NGS-sequencing technology

90 to screen three times the number of samples and 10,000 times the number of genetic loci

91 relative to previous work, and use the resulting data to re-evaluate patterns of population 
92 structure in American Kestrels across their U.S. and Canadian breeding distribution.

93 Specifically, we ask the following research questions: (1) Does genome-wide SNP data

94 provide higher resolution of population structure than previous work based on fewer

95 markers?, (2) How does the resulting population genetic structure relate to previously

96 defined subspecies boundaries and variation in migratory behavior across the range?, and

97 (3) How can the resulting genoscape be used help identify genetically distinct populations

98 and develop hypotheses to explain regional variation in demographic trends?

100 METHODS

101 Sample collection and DNA extraction

102 Genetic samples were collected from 683 breeding adult or nestling American Kestrels

103 from across the breeding range in North America in collaboration with several non-profit

104 organizations, state agencies, university researchers, and citizen scientists (Table 1,

105 Appendix 1). Blood $(\sim 30 \mu \mathrm{l})$ or pin feather samples were collected from 287 individuals

106 for the construction of Restriction Site Associated DNA sequencing (RADseq) libraries.

107 Blood was collected via brachial or jugular venipuncture, preserved in Queen's lysis

108 buffer (Seutin et al. 1991) and stored at $-80^{\circ} \mathrm{C}$ or 3-4 pin feathers containing a small

109 amount of blood in the base of the feather were collected from the breast of one nestling

110 per brood and stored in envelopes at room temperature. The remainder of the feather

111 samples used for high throughput SNP analyses $(n=396)$ were collected from the breast

112 of adult birds and stored in envelopes at room temperature. All samples were extracted

113 using a QIAGEN DNeasy® Blood and Tissue Kits (San Francisco, CA) and blood and

114 pin feather extractions were further quantified using Qubit dsDNA HS157 Assay kits 
115 (ThermoFisher Scientific) and visually inspected via gel electrophoresis to ensure

116 selection of high quality, intact DNA for construction of RADseq libraries. Remaining

117 tissue and blood samples, as well as remaining extractions, were currated and made

118 available for future use in -20 and -80 freezers respectively in the Conservation

119 Genomics Laboratory at Colorado State University.

121 Genome sequencing, assembly and annotation

122 To create a reference genome, the Illumina TruSeq DNA PCR-Free LT kit (Illumina) was

123 used to prepare a genomic DNA library from a single individual from Boise, Idaho,

124 following the adjustments made by Ruegg et al. (2018). The resulting library was

125 sequenced on two lanes of an Illumnia HiSeq2500 using 250 base-pair (bp) paired-end

126 sequencing at the DNA Technologies and Expression Analysis Cores at the UC Davis

127 Genome Center (Davis, CA). Initial contigs were assembled with the Discovar DeNovo

128 assembler from the Broad Institute (http://www.broadinstitute.org), discarding contigs

129 less than $1000 \mathrm{bp}$ in length. We also sequenced mate pair libraries with two insert sizes

130 (4kb and $8 \mathrm{~kb}$ ) on one third of an Illumina HiSeq2500 2x100bp lane at the University of

131 Utah Huntsman Cancer Center. Mate pair reads were trimmed with NxTrim (O’Connell

132 et al. 2015) and scaffolds were generated with both paired end and mate pair libraries

133 with SSPACE (overlap requirement k=3; Boetzer et al. 2011). The assembly was then

134 broken at likely error regions using REAPR (Hunt et al. 2013) and SSPACE scaffolding was

135 repeated with $\mathrm{k}=5$ and scaffolds less than $1000 \mathrm{bp}$ were discarded for the final assembly. 
This is an author-produced, peer-reviewed version of this article. The final, definitive version of this document can be found online at Auk: Ornithological Advances, published by Oxford University Press on behalf of the American Ornithological Society. Copyright restrictions may apply. https://doi.org/10.1093/auk/ukaa051. The content of this document may vary from the final published version.

137 For annotation purposes, REPEATMASKER (-species birds) (Tarailo-Graovac and Chen

138 2009) was used to replace repetitive regions of the final genome assembly with N's. Two

139 different ab initio gene predictions were used within the MAKER pipeline (Cantarel et al.

140 2008): SNAP and Augustus. The Zebra Finch (Taeniopygia guttata) cDNA and protein

141 sequences were downloaded from Ensembl and used to train SNAP, and the available

142 chicken (Gallus gallus domesticus) training dataset was used to train AUGUSTUS.

143 ITERPROSCAN (Zdobnov and Apweiler 2001) was used to add Pfam protein annotation

144 and gene ontology (GO) terms and identified 13,342 genes.

146 SNP discovery and SNP filtering

147 High-density RADseq was carried out on 287 individuals from 12 sampling locations

148 following a modified version of the bestRAD library preparation protocol (SI Table 1;

149 Ali et al. 2016). In short, DNA was normalized to a final concentration of 100ng in a

150 10ul volume, digested with restriction enzyme SBfl (New England Biolabs, NEB). The

151 fragmented DNA was then ligated with SBfI specific adapters prepared with biotinylated

152 ends and samples were pooled and cleaned using 1X Agencourt ${ }^{\circledR}$ AMPure XP beads

153 (Beckman Coulter). Pooled and clean libraries were sheared to an average length of

154 400bp with 10 cycles on the Bioruptor NGS sonicator (Diagenode) to ensure appropriate

155 length for sequencing and an Illumina NEBNext Ultra DNA Library Prep Kit (NEB) was

156 used to repair blunt ends and ligate on NEBNext Adaptors to the resulting DNA

157 fragments. Agencourt ${ }^{\circledR}$ AMPure XP beads (Beckman Coulter) were then used to select

158 DNA fragments with an average length of 500bp, libraries were enriched with PCR, and

159 cleaned again with Agencourt ${ }^{\circledR}$ AMPure XP beads. The resulting libraries were 
This is an author-produced, peer-reviewed version of this article. The final, definitive version of this document can be found online at $A u k$ : Ornithological Advances, published by Oxford University Press on behalf of the American Ornithological Society. Copyright restrictions may apply. https://doi.org/10.1093/auk/ukaa051. The content of this document may vary from the final published version.

160 sequenced on three lanes of an Illumina HiSeq 2500 at the UC Davis Genome Center

161 using 250 base pair, paired-end sequencing, and 66 individuals with low coverage were

162 re-sequenced on a fourth lane.

163

164 The program STACKS (Catchen et al. 2013) was used to demultiplex, filter and trim

165 adapters from the data with the process_radtags function and remove duplicate read pairs

166 using the clone_filter function. BOWTIE2 was used to map reads to the genome

167 (Langmead and Salzberg 2012), and the HaplotypeCaller in the Genome Analysis Toolkit

168 was used to identify SNPs (McKenna et al. 2010, Auwera et al. 2013). VCFTOOLS

169 (Danecek et al. 2011) was used to remove indels, non-biallelic SNPs, and low quality and

170 rare variants (genotype quality 20; coverage depth 10; minor allele frequency 0.05 ). The

171 final number of SNPs and individuals to be retained for further analyses was assessed by

172 visualizing the tradeoff between discarding low-coverage SNPs and discarding

173 individuals with missing genotypes using custom scripts within the R-package

174 GENOSCAPERTOOLS (Anderson 2019). Because preliminary analyses revealed outliers in

175 the principal components analysis and we were concerned about sample contamination

176 among individuals during the library preparation stage, we filtered out individuals with

$177>40 \%$ heterozygosity as heterozygosity is expected to be higher then expected in cases

178 where multiple individuals are combined into a single well (SI Figure 2).

\section{Identification of outlier SNPs for Population Assignment}

181 Population genomic analyses were conducted on all SNPs that passed our filters to assess

182 genome-wide patterns of genetic divergence and identify SNPs for population assignment 
This is an author-produced, peer-reviewed version of this article. The final, definitive version of this document can be found online at $A u k$ : Ornithological Advances, published by Oxford University Press on behalf of the American Ornithological Society. Copyright restrictions may apply. https://doi.org/10.1093/auk/ukaa051. The content of this document may vary from the final published version.

183 and assay design. Population genetic structure was assessed by calculating pairwise

184 population level $F_{S T}$ (with different sampling sites representing different populations)

185 with bootstrapped confidence intervals using the R package ASSIGNER (Gosselin et al.

186 2019), and principal components analysis (PCA) using SNPRELATE (Zheng et al. 2012).

187 To test for isolation by distance we compared linearized $F_{S T}$ with pairwise geographic

188 distance calculated from the central longitudinal and latitudinal coordinates of each

189 location using the Vincenty ellipsoid method in the R package GEOSHPERE (Hijmans

190 2019). Because the PCA of all SNPs from the genome-wide analysis revealed five major

191 groups, including Alaska, Texas, the west, the east and Florida (see results, Figure 1),

192 subsequent analyses focused on developing SNPs for population assignment within and

193 among these groups.

195 To identify SNPs useful for population assignment between the 5 genetically distinct

196 populations, we used VCFTOOLS (Danecek et al. 2011) to calculate site-wise $F_{S T}$ between

197 populations and identify individual SNPs with the most power for discriminating between

198 populations (SNPs with the biggest allele frequency differences). It is important to note

199 that population genetic summary statistics were based on the full RADseq data set (see

200 above) rather than downstream SNP dataset in order to avoid potential biases associated

201 with selecting SNPs with the highest discriminatory power for population assignment.

202 Custom R-scripts were used to evaluate which of our top-ranking SNPs would generate

203 designable assays based on the following parameters: 1) Guanine-Cytocene content

204 was less than $0.65,2$ ) there were no insertions or deletions (indels) within $30 \mathrm{bp}$ of the

205 variable site, or 3) there were no ambiguous codes within 20bp of the variable site. 
206 Additionally, we used BWA-MEM (Burrows-Wheeler Aligner; Li and Durbin 2009) to

207 determine which of our designable SNPs mapped uniquely to the reference genome.

208 Fluidigm SNPtype assays (Fluidigm Inc.) were then developed in the 216 top ranking

209 SNPs that passed our filters.

211 Genetic screening and building the genoscape

212 Ninety-three samples and three non-template controls were screened on the Fluidigm

213 Corporation EP1 Genotyping System (Fluidigm Inc.) and assays were ranked by

214 variability and call rate to identify the most reliable 192 SNP assays of 216 that were

215 designed. The 192 variable SNP assays with the highest call rate were used to screen an

216 additional 396 American Kestrel feather samples from 34 breeding locations in the

217 United States and Canada in order to fill in sampling gaps and refine the resulting map of

218 population genetic structure (Table 1). Following the methods described in Ruegg et al.

219 (2014), we amplified PCR products using fluorescently labelled allele-specific primers

220 and then used the EP1 Array Reader and Fluidigm's automated Genotyping Analysis

221 Software (Fluidigm Inc.) to call alleles with a confidence threshold of $90 \%$. Each

222 genotype was also visually inspected for potential irregularities and uncertain genotype

223 calls were removed from the analysis. Samples with missing genotypes at $>25 \%$ of SNP

224 assays were removed from the analyses and SNP loci with $>25 \%$ missing genotypes were

225 removed, resulting in a total of 376 additional individuals at 186 SNP loci that could be

226 used to identify genetic structure across the range (Table 1). 
228 The final analysis of population genetic structure at 186 loci was conducted on a subset

229 of the loci from the RADseq dataset combined with the SNP genotype-only dataset for a

230 total of 683 individuals. The program structure (version 2.3.4; Pritchard et al. 2000) was

231 used to assess how genetic variation is distributed across geographic space. The

232 admixture model with the locprior option was run with uncorrelated allele frequencies, a

233 burn-in period of 50,000, a total run length of 150,000 and assuming the number of

234 genetic clusters $(\mathrm{K})$ ranged from 1 to 10 (with 5 iterations run at each assumed value of

$235 \mathrm{~K})$. We used the Evanno method to determine the number of genetic clusters. The

236 Evanno method (Evanno et al. 2005), implemented in POPHELPER in R (Francis 2017), is

237 an ad hoc method to determine the most probable number of population genetic clusters

238 based on the rate of change in the log probability of data between successive $K$ values.

239 We used this algorithm to detect the uppermost hierarchical level of structure across the

240 Kestrel breeding range and visually inspected subsequent structure plots to identify

241 regions where geographic barriers to gene flow exist and/or where admixture

242 homogenizes population structure. The resulting posterior probabilities of genetic group

243 membership estimated from structure were visualized as transparency levels of different

244 colors overlaid upon a base map from Natural Earth (naturalearthdata.com) and clipped

245 to a map of the American Kestrel breeding range (NatureServe 2012), making use of the

246 R packages SP, RGDAL, and RASTER (Bivand et al. 2013, 2017; Hijmans 2017). We scaled

247 the transparency of colors within each distinguishable group, so that the highest posterior

248 probability of membership in the group according to structure is opaque and the smallest

249 is transparent. This creates a spatially-explicit map of the population structure analysis

250 that we call the genoscape of the American Kestrel (Figure 2). 
251 RESULTS

252 Genome sequencing, assembly and annotation

253 The final American Kestrel genome assembly is $1.23 \mathrm{~Gb}$ in length and consists of 5,096

254 scaffolds with an N50 of 941kb.

255

256 SNP discovery and SNP filtering

257 RAD-sequencing data from 287 individuals resulted in the identification of 199,705 bi-

258 allelic loci with a minor allele-frequency greater than 5\%, minimum quality score greater

259 than 20, and minimum per individual sequencing depth greater than 10. After assessing

260 the tradeoff between low coverage SNPs and missing genotypes (SI Figure 1), the data

261 were further filtered to include 197 individuals, 12 populations, and 75,000 loci; 2

262 populations, one in CA and one in Idaho (Table 1), were subsequently dropped for the

263 purposes of population genetic analyses as a result of low sample size $(n<3)$. Seven

264 outlier individuals with greater than $>40 \%$ heterozygosity were also subsequently

265 removed to avoid inclusion of samples potentially subject to contamination (as indicated

266 by a histogram of the distribution of heterozygosity across all individuals which showed

267 individuals above this threshold to be clear outliers, SI Figure 2). The final RADseq data

268 set consisted of 197 individuals and 72,263 SNPs.

$270 \quad$ Population genetic structure

271 Significant pairwise $\mathrm{F}_{S T}$ between the 10 sampling locations ( 2 were filtered out because

272 they had fewer than 4 individuals, see above) ranged from 0.0010-0.0162 (Table 2). The

273 positive correlation between $F_{S T}$ and geographic distance $\left(\mathrm{r}^{2}=0.123\right.$; p-value $\left.=0.01\right)$ 
274 suggests that isolation by distance contributes to genetic differentiation across the range.

275 Overall, $F_{S T}$ was highest between non-migratory Florida and Texas sampling locations,

276 while the genetic differentiation was the lowest among sampling locations within Eastern

277 and Western breeding areas (Table 2). Principal components analysis based on 72,263

278 RAD-sequence loci revealed 4 main clusters with East, West, and Florida falling out

279 separately, while Alaska and Texas overlapped (Figure 1). Principal component 1 was

280 strongly influenced by data missingness, while PC2 and PC3 reflected differences in

281 geography. Although there was overlap in principal component space between Texas and

282 Alaska along PC2 and PC3, these groups were separated in the subsequent PC axes and

283 in the search for loci representative of the observed population structure based on

284 significant pairwise $\mathrm{F}_{S T \text { s }}$ and geographic distance. Overall, the first three principal

285 components explained less than $3 \%$ of the total variation in allele frequencies.

Genoscape Construction / Structure Results

288 We successfully genotyped 376 samples collected from 34 breeding locations in the

289 United States and Canada using the final panel of 192 SNP-type assays for population

290 assignment (Table 1). Running structure with $K$ ranging from 1 to 10 revealed the

291 strongest support for $K=5$, where the plateau of delta $K$ (i.e. the greatest change in $\mathrm{K}$ )

292 supports the uppermost hierarchical level of structure being $K=3$ (SI Figure 3A; Evanno

293 et al. 2005, Pritchard et al. 2000); however, subsequent increases of $K$, until $K=$

2945 , reduced the log likelihood of the model and the addition of the Florida $(K=4)$ and

295 Alaskan populations $(K=5)$ were biologically feasible (SI Figure 4), suggesting that

296 American Kestrel's can be separated into 5 genetically distinct populations. Ultimately, 
This is an author-produced, peer-reviewed version of this article. The final, definitive version of this document can be found online at Auk: Ornithological Advances, published by Oxford University Press on behalf of the American Ornithological Society. Copyright restrictions may apply. https://doi.org/10.1093/auk/ukaa051. The content of this document may vary from the final published version.

297 we find genetic distinctness of the residential Texas population, the residential Florida $F$.

298 s. paulus subspecies, as well as distinct clustering of the Eastern and Western migratory

299 populations, and an Alaskan migratory population (Figure 2).

301 DISCUSSION

302 Identifying distinct units for conservation is an important first step in the management of

303 declining populations (Allendorf and Luikart 2007, Funk et al. 2012). Historically,

304 conservation biologists have used a combination of morphological, behavioral, and

305 genetic variation to define management or conservation units within species and these

306 have sometimes, but not always, corresponded to subspecies boundaries. Here we

307 generate a genoscape for the American Kestrel by sequencing the first American Kestrel

308 genome, assessing population structure at 72,263 SNP markers screened in 12

309 populations from across the US and Canada migratory and non-migratory range, and

310 validating patterns of population structure at 192 SNP markers screened in 34

311 populations. In contrast to previous work based on a more limited number of samples

312 and markers that detected no major signals of population structure across the breeding

313 range (Miller et al. 2012), our genoscape supports the existence of five genetically-

314 distinct populations within American Kestrels found breeding across Canada and the

315 United States (East, West, Alaska, Texas and Florida), one of which correlates with the

316 previously identified southeastern subspecies (F. s. paulus). Overall, the most significant

317 genetic differences occurred between the two resident populations (Texas and Florida),

318 followed by differences between resident and migratory populations, and regional

319 separation of Eastern and Western breeding populations. Here we discuss the utility of 
320 the resulting genoscape for clarifying the relationship between previously defined

321 subspecies boundaries and genetically distinct populations identified using genome-wide

322 genetic data, as well as for providing a framework for developing hypotheses regarding

323 drivers of regional variation in demographic trends.

325 The question of whether subspecies represent defensible taxonomic units has been

326 controversial in the past because some molecular studies have failed to identify

327 subspecies as phylogenetically distinct (Barrowclough 1980, Mayr and Ashlock 1991,

328 O'brien and Mayr 1991, Ball and Avise 1992, Burbrink et al. 2000). Further, discord in

329 location of subspecies boundaries often arises when there are mismatches in the

330 timescales over which divergence occurs in various datasets; for example, subspecies

331 boundaries based on neutral genetic markers often diverge from subspecies boundaries

332 identified based on genetic or morphological markers that may be under selection (Haig

333 and Winker 2010). Using genome-wide sequencing, we found support for genetic

334 differentiation between the two US and Canadian subspecies of American Kestrels

335 breeding North of Mexico, F. s. paulus (southeastern) and F. s. sparverius (remainder of

336 the US and Canadian breeding range), but also found that divergence between the

337 subspecies is similar in magnitude to the degree of divergence detected between resident

338 F. s. sparverius in Texas and their migratory counterparts to the North. In general, levels

339 of genetic differentiation across the range were low and pairwise genetic distance versus

340 geographic distance suggest that patterns of divergence are in large part explained by

341 isolation by distance. Such low levels of differentiation are consistent with past studies of

342 American Kestrels based on fewer loci (Miller et al. 2012) and suggest that gene flow 
343 may homogenize the diversifying effects of local adaptation and drift in high dispersal

344 species like Kestrels (Willoughby et al. 2017; Doyle et al. 2018; Medina et al. 2018).

345 While our genome-wide genetic analysis supports the existence of $F$. s. paulus as a

346 genetically distinct subspecies, it also suggests that weak population structure within

347 American Kestrels relates as much to migratory phenotype as it does to subspecies

348 boundaries per se.

350 One possible explanation for the putative relationship between genetic differentiation and

351 migratory phenotype in American Kestrels is that dispersal is limited between distinct

352 migratory phenotypes, as has been found in other migratory systems (reviewed within

353 Turbek et al. 2018). Like most raptors, Kestrels in Eastern and Western North America

354 follow a strong north-to-south pattern of migration, with little longitudinal drift (Mueller

355 and Berger 1967, Evans and Rosenfield 1985, Goodrich and Smith 2008). Additionally,

356 the frequency of long-distance migration into Mexico is thought to increase from east to

357 the west (Mueller \& Berger 1967; Evans \& Rosenfield 1985; Goodrich \& Smith 2008),

358 supporting the idea that Eastern and Western populations have different overwintering

359 locations. One explanation for the observed genetic break in central North America is

360 that separate Eastern and Western migratory routes and overwintering locations have

361 resulted in the evolution of a weak migratory divide where gene flow is limited as a result

362 of reproductive isolation between distinct migratory phenotypes, as has been documented

363 across migratory divides in other avian taxa (reviewed within Turbek et al. 2018).

364 Alternatively, the observed genetic break between Eastern and Western populations may

365 have nothing to do with migratory phenotype per se, but instead may result from low 
This is an author-produced, peer-reviewed version of this article. The final, definitive version of this document can be found online at Auk: Ornithological Advances, published by Oxford University Press on behalf of the American Ornithological Society. Copyright restrictions may apply. https://doi.org/10.1093/auk/ukaa051. The content of this document may vary from the final published version.

366 population density in Central North America (an additive effect of Isolation-by-Distance)

367 limiting gene flow between eastern and western groups (Winker et al 2010). Future work

368 will focus on quantifying migratory phenotypes in American Kestrels across their North

369 American range and assessing the relative contribution of migration and isolation by

370 distance to patterns of genetic divergence in this and other species with similar variation

371 in migratory phenotypes.

372

373 An alternative explanation for higher levels of divergence between resident and

374 migratory $F$. sparverius populations in our study is that divergence is not caused by

375 differences in migratory phenotype, but instead results from gene flow between resident

376 forms in Texas and Florida (F. s. Paulus) and resident subspecies further to the south (F.

377 s. peninsularis from Baja and W. Mexico, and F. s. sparverioides from Cuba). Previous

378 work suggests $F$. s. sparverius may hybridize with $F$. s. peninsularis in northern and

379 eastern Arizona (Bond 1943), but here we successfully genotyped 15 samples from

380 breeding migratory $F$. s. sparverius from Arizona and found that they all assigned clearly

381 to the western migratory group of $F$. s. sparverius rather than to the resident Texas

382 group. This result is opposite of what we would expect if high levels of divergence

383 between Texas residents and their migratory counterparts to the North was due to

384 hybridization between Texas birds and the F. s. peninsularis subspecies to the

385 South. While to the best of our knowledge, there are no known records of hybridization

386 between F. s. sparverioides from Cuba and F. s. paulus from Florida, eBird records of

387 kestrels from extreme southeastern Florida during the summer support the possibility that

388 F. s. sparverioides vagrants may occur within the same region. However, gene flow is 
This is an author-produced, peer-reviewed version of this article. The final, definitive version of this document can be found online at $A u k$ : Ornithological Advances, published by Oxford University Press on behalf of the American Ornithological Society. Copyright restrictions may apply. https://doi.org/10.1093/auk/ukaa051. The content of this document may vary from the final published version.

389 unlikely, given the infrequent ( $<1$ per year) sightings of kestrels in southeastern Florida

390 and the fact that the nearest breeding population of $F$. s. paulus is $>150 \mathrm{~km}$ to the north

391 (FWC 2003). Thus, while on-going gene flow with resident subspecies to the south seems

392 like an unlikely explanation for the observed patterns of divergence between resident and

393 migratory populations north of Mexico, more extensive sampling south of the United

394 States border is needed to fully test all alternative hypotheses.

396 Heterogeneity in patterns of American Kestrel population decline across North America

397 suggest that regional populations are experiencing different threats and / or are

398 responding to the same threats differently (Butcher 1990, Smallwood et al. 2009, Sauer et

399 al. 2014, McClure et al. 2017), but past analyses have been limited by the lack of

400 genetically distinct populations. The results presented herein demonstrate the utility of

401 the genoscape approach for identifying five genetically distinct populations of American

402 Kestrels - East, West, Alaska, Texas and Florida, which can serve as the foundation for

403 the development of hypotheses to explain regional variation in demographic trends. For

404 example, while interpreting patterns of population decline from existing datasets is

405 complicated by known northward shifts in distribution (Paprocki et al. 2014), migration

406 count data from the Raptor Population Index project between 2006-2016 support the idea

407 that western populations have largely remained stable or are increasing, while eastern

408 populations are largely declining (SI Figure 3; Brandes et al. 2016, Crewe et al. 2016). In

409 addition, work focused specifically on understanding responses of American Kestrels to

410 climate change in the last decade supports the hypothesis that western populations are

411 migrating shorter distances and breeding earlier (Heath et al. 2012), while corresponding 
412 changes in the east have not been documented. In light of the genoscape results

413 presented herein, one hypothesis that warrants further exploration is that genetically-

414 based differences in phenology between Eastern and Western groups affect population-

415 specific responses to changing climate conditions, resulting in population decreases in the

416 east, but not the west.

417

418 In conclusion, the American Kestrel genoscape reveals previously undetected levels of

419 population structure among Eastern, Western, Alaska, Texas and Florida populations.

420 While our data support the existence $F$. s. sparverius and F. s. paulus subspecies as

421 genetically distinct groups, it also suggests that genetic differentiation is more closely

422 tied to migratory phenotype (resident, long-distance, and short-distance migrants) than to

423 previously defined subspecies boundaries. Based on our results, we suggest it would be

424 ecologically appropriate to establish five management areas corresponding to the five

425 genetically unique populations identified by our genoscape. More importantly, when the

426 resulting genetically distinct populations are paired with data from existing long-term

427 monitoring efforts, such as the Raptor Population Index, the results can be used to test

428 hypotheses regarding drivers of observed population-specific responses to climate change

429 and other stressors.

$432 \quad$ Literature Cited

433 Ali, O. A., S. M. ORourke, S. J. Amish, M. H. Meek, G. Luikart, C. Jeffres, and M. R. $434 \quad$ Miller (2016). RAD capture (Rapture): Flexible and efficient sequence-based 435 genotyping. Genetics 202:389-400. 
This is an author-produced, peer-reviewed version of this article. The final, definitive version of this document can be found online at $A u k$ : Ornithological Advances, published by Oxford University Press on behalf of the American Ornithological Society. Copyright restrictions may apply. https://doi.org/10.1093/auk/ukaa051. The content of this document may vary from the final published version.

436 Allendorf, F. W., and G. Luikart (2007). Management units. In Conservation and the Genetics of Populations. 16.5.3. Blackwell Publishing, Oxford, UK.

Anderson, E. (2019). genoscapeRtools: Tools for building migratory bird genoscapes. R package version 0.1.0.

Auwera, G. A. V. der, M. O. Carneiro, C. Hartl, R. Poplin, G. del Angel, A. LevyMoonshine, T. Jordan, K. Shakir, D. Roazen, J. Thibault, E. Banks, et al. (2013). From FastQ data to high-confidence variant calls: The Genome Analysis Toolkit best practices pipeline. Current Protocols in Bioinformatics 43:11.10.1-11.10.33.

Ball, R. M., and J. C. Avise (1992). Mitochondrial DNA phylogeographic differentiation among avian populations and the evolutionary significance of subspecies. The Auk 109:626-636.

Barrowclough, G. F. (1980). Genetic and phenotypic differentiation in a Wood Warbler (Genus Dendroica) hybrid zone. The Auk 97:655-668.

Benestan, L., T. Gosselin, C. Perrier, B. Sainte-Marie, R. Rochette, and L. Bernatchez (2015). RAD genotyping reveals fine-scale genetic structuring and provides powerful population assignment in a widely distributed marine species, the American lobster (Homarus americanus). Molecular Ecology 24:3299-3315.

Bird, D. M. (2009). The American Kestrel: From common to scarce? Journal of Raptor Research 43:261-262.

Bird, D. M., and R. S. Palmer (1988). American Kestrel. In Handbook of North American Birds. Palmer RS. Yale University Press, New Haven, CT, pp. 253-290.

Bivand, R., T. Keitt, and B. Rowlingson (2017). rgdal: Bindings for the "Geospatial" Data Abstraction Library. R package version 1.4-8. https://CRAN.Rproject.org/package $=$ rgdal

Bivand, R. S., E. Pebesma, and V. Gómez-Rubio (2013). Applied spatial data analysis

Boetzer, M., C. V. Henkel, H. J. Jansen, D. Butler, and W. Pirovano (2011). Scaffolding with R. Springer.

464 Bond, R. M. (1943). Variation in Western Sparrow Hawks. The Condor 45:168-185.

465 Brandes, D., D. Oleyar, S. Hoffman, and L. Goodrich (2016). The raptor population index, 2016 regional trend summaries and conservation assessments.

467 Burbrink, F. T., R. Lawson, and J. B. Slowinski (2000). Mitochondrial DNA 468 phylogeography of the polytypic North American rat snake (Elaphe obsoleta): A 
critique of the subspecies concept. Evolution; International Journal of Organic Evolution 54:2107-2118.

471

472

473

474

475

476

477

478

479

480

481

482

483

484

485

486

487

488

489

490

491

492

493

494

495

496

497

498

499

500

501

502

503

Bussche, R. A. V. D., M. E. Judkins, M. J. Montague, and W. C. Warren (2017). A resource of genome-wide single nucleotide polymorphisms (SNPs) for the conservation and management of golden eagles. Journal of Raptor Research 51:368-377.

Butcher, G. S. (1990). Audubon Christmas bird counts, pp. 5-13 in J.R. Sauer and S. Droege, eds. U.S. Fish and Wildlife Service 90(1).

Cantarel, B. L., I. Korf, S. M. C. Robb, G. Parra, E. Ross, B. Moore, C. Holt, A. Sánchez Alvarado, and M. Yandell (2008). MAKER: An easy-to-use annotation pipeline designed for emerging model organism genomes. Genome Research 18:188-196.

Catchen, J., P. A. Hohenlohe, S. Bassham, A. Amores, and W. A. Cresko (2013). Stacks: An analysis tool set for population genomics. Molecular ecology 22:3124-3140.

Crewe, T., P. Taylor, D. Lepage, L. Goodrich, J. Brown, and J. Sodergren (2016). The raptor population index, 2016 analysis methods and trend results. [Online.] Available at http://rpi-project.org/2016/.

Danecek, P., A. Auton, G. Abecasis, C. A. Albers, E. Banks, M. A. DePristo, R. E. Handsaker, G. Lunter, G. T. Marth, S. T. Sherry, G. McVean, et al. (2011). The variant call format and VCFtools. Bioinformatics 27:2156-2158.

Doyle, J. M., D. A. Bell, P. H. Bloom, G. Emmons, A. Fesnock, T. E. Katzner, L. LaPré, K. Leonard, P. SanMiguel, R. Westerman, and J. Andrew DeWoody (2018). New insights into the phylogenetics and population structure of the Prairie Falcon (Falco mexicanus). BMC Genomics 19:233.

Egger, B., M. Roesti, A. Böhne, O. Roth, and W. Salzburger (2017). Demography and genome divergence of lake and stream populations of an East African cichlid fish. Molecular Ecology 26:5016-5030.

Evanno, G., S. Regnaut, and J. Goudet (2005). Detecting the number of clusters of individuals using the software STRUCTURE: A simulation study. Molecular Ecology 14:2611-2620.

Evans, D. L., and R. N. Rosenfield (1985). Migration and mortality of Sharp-shinned Hawks ringed at Duluth, Minnesota, USA. ICBP Technical Publication 5:311316.

Farmer, C. J., and J. P. Smith (2009). Migration monitoring indicates widespread declines of American Kestrels (Falco sparverius) in North America. Journal of Raptor Research 43:263-273. 
504 Ferguson-Lees, J., and D. A. Christie (2006). Raptors of the world. Princeton University

$505 \quad$ Press, Princeton, N.J.

506 Florida Fish and Wildlife Conservation Commission (2003). Florida's breeding bird atlas: A collaborative study of Florida's birdlife. http://myfwc.com/bba (Date accessed 01/06/2003).

509 Francis, R. M. (2017). pophelper: An R package and web app to analyse and visualize population structure. Molecular Ecology Resources 17:27-32.

511 Fredrickson, R. J., P. W. Hedrick, R. K. Wayne, B. M. vonHoldt, and M. K. Phillips (2015). Mexican wolves are a valid subspecies and an appropriate conservation target. Journal of Heredity 106:415-416.

Freer, J. J., B. K. Mable, G. Clucas, A. D. Rogers, M. J. Polito, M. Dunn, R. Naveen, H. Levy, and T. Hart (2015). Limited genetic differentiation among Chinstrap penguin (Pygoscelis antarctica) colonies in the Scotia Arc and Western Antarctic Peninsula. Polar Biology 38:1493-1502.

Funk, W. C., J. K. McKay, P. A. Hohenlohe, and F. W. Allendorf (2012). Harnessing genomics for delineating conservation units. Trends in ecology \& evolution 27:489-496.

Funk, W. C., T. D. Mullins, and S. M. Haig (2007). Conservation genetics of Snowy Plovers (Charadrius alexandrinus) in the Western Hemisphere: Population genetic structure and delineation of subspecies. Conservation Genetics 8:12871309.

Goodrich, L. J., and J. P. Smith (2008). Raptor migration in North America. In State of North America's Birds of Prey. K.L. Bildstein KL, Smith JP, Ruelas Inzunza E \& Veit RR. Series in Ornithology 3:37-149.

Gosselin, T., E. C. Anderson, and I. Bradbury (2019). assigner: Assignment analysis with GBS/RAD data using R. R package version 0.5 .6 .

Haig, S. M., and K. Winker (2010). Chapter 14: Avian subspecies: Summary and prospectus - Subespecies de aves: Síntesis y perspectivas. Ornithological Monographs 67:172-175.

Heath, J. A., K. Steenhof, and M. A. Foster (2012). Shorter migration distances associated with higher winter temperatures suggest a mechanism for advancing nesting phenology of American kestrels Falco sparverius. Journal of Avian Biology 43:376-384.

537 Henny, C. J., and G. L. Brady (1994). Partial migration and wintering localities of American Kestrels nesting in the Pacific northwest. Northwestern Naturalist 75:7. 
539 Hijmans, R. (2019). geosphere: Spherical trigonometry. R package version 1.5-10.

540 https://CRAN.R-project.org/package=geosphere

541 Hijmans, R. J. (2017). raster: Geographic data analysis and modeling. R package version 3.1-5. https://CRAN.R-project.org/package=raster

543 Hinnebusch, D. M., J.-F. Therrien, M.-A. Valiquette, B. Robertson, S. Robertson, and K. L. Bildstein (2010). Survival, site fidelity, and population trends of American kestrels wintering in southwestern Florida. The Wilson Journal of Ornithology 122:475-483.

Hoffman, M. L., and M. W. Collopy (1988). Historical status of the American Kestrel

Hunt, M., T. Kikuchi, M. Sanders, C. Newbold, M. Berriman, and T. D. Otto (2013). REAPR: A universal tool for genome assembly evaluation. Genome Biology $14: R 47$.

Jahner, J. P., D. Gibson, C. L. Weitzman, E. J. Blomberg, J. S. Sedinger, and T. L. Parchman (2016). Fine-scale genetic structure among greater sage-grouse leks in central Nevada. BMC Evolutionary Biology 16:127.

Langmead, B., and S. L. Salzberg (2012). Fast gapped-read alignment with Bowtie 2. Nature Methods 9:357-359.

557 Larson, W. A., L. W. Seeb, M. V. Everett, R. K. Waples, W. D. Templin, and J. E. Seeb (2014). Genotyping by sequencing resolves shallow population structure to inform conservation of Chinook salmon (Oncorhynchus tshawytscha).

561 Layne, J. M. (1982). Analysis of Florida-related banding data for the American Kestrel. $562 \quad$ North American Bird Bander 7:94-99.

563 Li, H., and R. Durbin (2009). Fast and accurate short read alignment with Burrows$564 \quad$ Wheeler transform. Bioinformatics 25:1754-1760.

565 Mayr, E. (1982). Of what use are subspecies? The Auk 99:593-595.

566 Mayr, E., and P. D. Ashlock (1991). Principles of systematic zoology. McGraw-Hill.

567 McClure, C. J. W., S. E. Schulwitz, R. V. Buskirk, B. P. Pauli, and J. A. Heath (2017).

$568 \quad$ Commentary: Research recommendations for understanding the decline of American Kestrels (Falco sparverius) across much of North America. Journal of Raptor Research 51:455-464. 
This is an author-produced, peer-reviewed version of this article. The final, definitive version of this document can be found online at $A u k$ : Ornithological Advances, published by Oxford University Press on behalf of the American Ornithological Society. Copyright restrictions may apply. https://doi.org/10.1093/auk/ukaa051. The content of this document may vary from the final published version.

571 McKenna, A., M. Hanna, E. Banks, A. Sivachenko, K. Cibulskis, A. Kernytsky, K.

572 Garimella, D. Altshuler, S. Gabriel, M. Daly, and M. DePristo (2010). The

$573 \quad$ Genome Analysis Toolkit: A MapReduce framework for analyzing next-

574 generation DNA sequencing data. Genome Research 20:1297-303.

575 Medina, I., G. M. Cooke, and T. J. Ord (2018). Walk, swim or fly? Locomotor mode

576 predicts genetic differentiation in vertebrates. Ecology Letters 21:638-645.

577 Miller, M. P., T. D. Mullins, J. W. Parrish, J. R. Walters, and S. M. Haig (2012).

$578 \quad$ Variation in migratory behavior influences regional genetic diversity and structure

579

580 among American Kestrel populations (Falco sparverius) in North America. Journal of Heredity 103:503-514.

Morin, P. A., K. K. Martien, and B. L. Taylor (2009). Assessing statistical power of SNPs for population structure and conservation studies. Molecular Ecology Resources 9:66-73.

Moritz, C. (1994). Defining 'evolutionarily significant units' for conservation. Trends in ecology \& evolution 9:373-375.

Mueller, H. C., and D. D. Berger (1967). Wind drift, leading lines, and diurnal migration. Wilson Bulletin 79:50-63.

Mura-Jornet, I., C. Pimentel, G. P. M. Dantas, M. V. Petry, D. González-Acuña, A. Barbosa, A. D. Lowther, K. M. Kovacs, E. Poulin, and J. A. Vianna (2018). Chinstrap penguin population genetic structure: One or more populations along the Southern Ocean? BMC Evolutionary Biology 18:90.

O’Brien, S. J., and E. Mayr (1991). Bureaucratic mischief: Recognizing endangered species and subspecies. Science 251:1187-1188.

O’Connell, J., O. Schulz-Trieglaff, E. Carlson, M. M. Hims, N. A. Gormley, and A. J. Cox (2015). NxTrim: Optimized trimming of Illumina mate pair reads. Bioinformatics 31:2035-2037.

600 Pritchard, J. K., M. Stephens, and P. Donnelly (2000). Inference of population structure $601 \quad$ using multilocus genotype data. Genetics 155:945-959.

602 Rowe, H. C., S. Renaut, and A. Guggisberg (2011). RAD in the realm of next-generation 603 sequencing technologies. Molecular Ecology 20:3499-3502. 
604 Ruegg, K., R. A. Bay, E. C. Anderson, J. F. Saracco, R. J. Harrigan, M. Whitfield, E. H.

605 Paxton, and T. B. Smith (2018). Ecological genomics predicts climate

606

607 vulnerability in an endangered southwestern songbird. Ecology Letters 21:1085-

608

609

610

611

612

613 1096.

Ruegg, K. C., E. C. Anderson, K. L. Paxton, V. Apkenas, S. Lao, R. B. Siegel, D. F. DeSante, F. Moore, and T. B. Smith (2014). Mapping migration in a songbird using high-resolution genetic markers. Molecular Ecology 23:5726-5739.

Ryman, N., S. Palm, C. André, G. R. Carvalho, T. G. Dahlgren, P. E. Jorde, L. Laikre, L. C. Larsson, A. Palmé, and D. E. Ruzzante (2006). Power for detecting genetic divergence: Differences between statistical methods and marker loci. Molecular Ecology 15:2031-2045.

Sauer, J. R., J. E. Hines, J. E. Fallon, K. L. Pardieck, D. J. Ziolkowski, Jr, and W. A. Link (2014). The North American breeding bird survey, results and analysis 1966 2012. USGS Patuxent Wildlife Research Center 02.19.2014.

Seutin, G., B. N. White, and P. T. Boag (1991). Preservation of avian blood and tissue samples for DNA analyses. Canadian Journal of Zoology 69:82-90.

Smallwood, J. A. (1990). Kestrel and Merlin. Proceedings of the Southeast Raptor Management Symposium. B. A. Giron Pendelton, Washington D.C., pp. 29-37.

Smallwood, J. A., and D. M. Bird (2002). American Kestrel (Falco sparverius), version 2.0. In The Birds of North America, No. 602 (A. F. Poole and F. B. Gill, Editors). Cornell Lab of Ornithology, Ithaca, NY, USA.

Smallwood, J. A., M. F. Causey, D. H. Mossop, J. R. Klucsarits, B. Robertson, S. Robertson, J. Mason, M. J. Maurer, R. J. Melvin, R. D. Dawson, G. R. Bortolotti, et al. (2009). Why are American Kestrel (Falco sparverius) populations declining in North America? Evidence from nest-box programs. Journal of Raptor Research 43:274-282. elements in genomic sequences. In Current Protocols in Bioinformatics (A. D. Baxevanis, G. A. Petsko, L. D. Stein and G. D. Stormo, Editors). John Wiley \& Sons, Inc., Hoboken, NJ, USA.

637 Waples, R. S. (1998). Separating the wheat from the chaff: Patterns of genetic differentiation in high gene flow species. Journal of Heredity 89:438-450. 
639 Waples, R. S., P. B. Adams, J. Bohnsack, and B. L. Taylor (2007). A biological

640 framework for evaluating whether a species is threatened or endangered in a

641

642 significant portion of its range. Conservation Biology: The Journal of the Society for Conservation Biology 21:964-974.

Willoughby, J. R., M. Sundaram, B. K. Wijayawardena, M. C. Lamb, S. J. A. Kimble, Y. Ji, N. B. Fernandez, J. D. Antonides, N. J. Marra, and J. A. Dewoody (2017). Biome and migratory behaviour significantly influence vertebrate genetic

Winker, K. (2010). Chapter 1: Subspecies represent geographically partitioned variation, diversity. Biological Journal of the Linnean Society 121:446-457.

650 Zdobnov, E. M., and R. Apweiler (2001). InterProScan - an integration platform for the a gold mine of evolutionary biology, and a challenge for conservation.

Zheng, X., D. Levine, J. Shen, S. M. Gogarten, C. Laurie, and B. S. Weir (2012). A highperformance computing toolset for relatedness and principal component analysis

655 Zink, R. M. (2014). Comparison of patterns of genetic variation and demographic history in the greater sage-grouse (Centrocercus urophasianus): Relevance for conservation. Open Ornithology Journal 7:19-29. 
This is an author-produced, peer-reviewed version of this article. The final, definitive version of this document can be found online at $A u k$ : Ornithological Advances, published by Oxford University Press on behalf of the American Ornithological Society. Copyright restrictions may apply. https://doi.org/10.1093/auk/ukaa051. The content of this document may vary from the final published version.

Table 1. Sampling locations and sample type used in the construction of the genoscape map for American Kestrels. The samples are broken down into those used for the RADsequencing analysis (pre and post filters) and the SNP genotyping (pre and post filtering). State and Province location codes correspond to Figure 1, while letter location codes correspond to the locations on Figure 2.

\begin{tabular}{|c|c|c|c|c|c|c|c|c|}
\hline STUDY SITE & LATITUDE & LONGITUDE & SAMPLE TYPE & $\mathbf{N}_{\text {RAD_NoFilter }}$ & $\mathbf{N}_{\text {RAD_Filter }}$ & $\mathbf{N}_{\text {SNP_NoFilter }}$ & $\mathbf{N}_{\text {SNP_NoFilter }}$ & $\begin{array}{l}\text { LOCATION CODE } \\
\text { Fig } 1 \text { / Fig } 2 \\
\end{array}$ \\
\hline ALBERTA, CANADA & 56.16262 & -117.34 & Feather & & & 12 & 12 & $\mathrm{E}$ \\
\hline ALASKA, USA & 63.96041 & -145.136 & Blood, feather & 25 & 18 & 7 & 7 & $\mathrm{AK} / \mathrm{A}$ \\
\hline ARIZONA, USA & 33.45007 & -111.943 & Feather & & & 20 & 15 & G \\
\hline CALIFORNIA (1), USA & 37.23551 & -120.244 & Blood, feather & 26 & 10 & 22 & 22 & CA / D1 \\
\hline CALIFORNIA (2), USA & 33.7315 & -117.878 & Blood, feather & 4 & 1 & 3 & 3 & CA / D2 \\
\hline CONNECTICUT (1), USA & 41.95001 & -73.364 & Feather & & & 10 & 10 & Y1 \\
\hline CONNECTICUT (2), USA & 41.94374 & -72.5072 & Feather & & & 10 & 7 & Y2 \\
\hline DELAWARE, USA & 39.75047 & -75.6969 & Feather & & & 4 & 4 & w \\
\hline FLORIDA, USA & 29.54151 & -82.2334 & Blood, feather & 18 & 16 & 20 & 20 & $\mathrm{FL} / \mathrm{AA}$ \\
\hline IDAHO (1), USA & 43.51209 & -116.377 & Blood, feather & 33 & 29 & 18 & 11 & ID / F1 \\
\hline IDAHO (2), USA & 43.27597 & -115.003 & Blood, feather & 9 & 2 & 6 & 5 & ID / F2 \\
\hline ILLINOIS, USA & 38.30563 & -89.7969 & Feather & & & 5 & 3 & $P$ \\
\hline KANSAS, USA & 38.77533 & -95.2486 & Feather & & & 4 & 4 & M \\
\hline MASSACHUSETTS, USA & 42.15064 & -71.8496 & Feather & & & 20 & 18 & z \\
\hline MICHIGAN (1), USA & 42.3216062 & -86.182447 & Feather & & & 6 & 6 & R1 \\
\hline MICHIGAN (2), USA & 44.9774725 & -85.712026 & Feather & & & 6 & 6 & R2 \\
\hline MICHIGAN (3), USA & 44.9034875 & -83.4873 & Feather & & & 8 & 8 & R3 \\
\hline MISSOURI (1), USA & 39.04824 & -94.3663 & Feather & & & 8 & 5 & $\mathrm{~N} 1$ \\
\hline MISSOURI (2), USA & 38.3804 & -90.925 & Feather & & & 1 & 1 & N2 \\
\hline MONTANA, USA & 45.76764 & -111.154 & Feather & & & 19 & 15 & 1 \\
\hline NORTH CAROLINA, USA & 35.73285 & -82.6776 & Feather & & & 17 & 16 & S \\
\hline NEBRASKA, USA & 40.99115 & -96.8957 & Feather & & & 6 & 6 & L \\
\hline NEW JERSEY, USA & 40.4297 & -74.9271 & Feather & & & 30 & 28 & $x$ \\
\hline NEW YORK, USA & 41.8773 & -74.7309 & Feather & & & 4 & 3 & $u$ \\
\hline OREGON (1), USA & 45.57362 & -123.048 & Blood, feather & 14 & 11 & 3 & 3 & OR / C1 \\
\hline OREGON (2), USA & 44.36466 & -121.412 & Feather & & & 25 & 24 & $\mathrm{C} 2$ \\
\hline PENNSYLVANIA, USA & 40.60183 & -75.5961 & Blood, feather & 37 & 23 & 13 & 13 & $\mathrm{PA} / \mathrm{V}$ \\
\hline SASKATCHEWAN, CANADA & 55.01968 & -105.893 & Blood, feather & 40 & 28 & 12 & 11 & SK / K \\
\hline TENNESSEE, USA & 35.14944 & -90.0489 & Feather & & & 5 & 5 & 0 \\
\hline TEXAS, USA & 33.63184 & -101.889 & Blood, feather & 13 & 12 & 1 & 1 & $\mathrm{TX} / \mathrm{B}$ \\
\hline UTAH, USA & 40.62255 & -111.987 & Feather & & & 30 & 28 & H \\
\hline VIRGINIA, USA & 38.6457 & -78.7522 & Blood, feather & 38 & 29 & 17 & 17 & $\mathrm{VA} / \mathrm{T}$ \\
\hline WISCONSIN, USA & 43.77114 & -89.4059 & Blood, feather & 30 & 18 & 24 & 24 & WI / Q \\
\hline WYOMING, USA & 43.60488 & -110.658 & Feather & & & 17 & 15 & J \\
\hline TOTAL & & & & 287 & 197 & 396 & 376 & \\
\hline
\end{tabular}


This is an author-produced, peer-reviewed version of this article. The final, definitive version of this document can be found online at Auk: Ornithological Advances, published by Oxford University Press on behalf of the American Ornithological Society. Copyright restrictions may apply. https://doi.org/10.1093/auk/ukaa051. The content of this document may vary from the final published version.

Table 2. Weighted mean pairwise Weir and Cockerham (1984) FST values (upper triangle) and confidence intervals (lower triangle) between all American kestrel sampling locations with greater than five individuals. Sampling locations correspond to those listed in Figure 1 and Table 1 and are organize dby approximate migration strategy. Color coding indicates degree of differentiation between locations with the greatest values of genetic divergence between nonmigratory populations in Florida and Texas.

\begin{tabular}{|c|c|c|c|c|c|c|c|c|c|c|c|}
\hline & & \multicolumn{2}{|l|}{\begin{tabular}{|c|} 
Complete Migrant \\
AK1
\end{tabular}} & \multicolumn{6}{|c|}{ Partial Migrant } & \multicolumn{2}{|c|}{ Resident } \\
\hline & & \begin{tabular}{|l} 
AK1 \\
\end{tabular} & SK1 & OR1 & ID1 & CA1 & WI1 & PA1 & VA1 & TX1 & FL1 \\
\hline \multirow{2}{*}{ Complete Migrant } & AK1 & - & 0.0031 & 0.0041 & 0.0048 & 0.0053 & 0.0060 & 0.0062 & 0.0086 & 0.0096 & 0.0124 \\
\hline & SK1 & $0.0028-0.0034$ & - & 0.0019 & 0.0016 & 0.0014 & 0.0015 & 0.0024 & 0.0046 & 0.0078 & 0.0103 \\
\hline \multirow{6}{*}{ Partial Migrant } & OR1 & $0.0036-0.0046$ & $0.0015-0.0023$ & - & 0.0025 & 0.0031 & 0.0046 & 0.0051 & 0.0073 & 0.0077 & 0.0112 \\
\hline & ID1 & $0.0044-0.0050$ & $0.0014-0.0019$ & $0.0021-0.0030$ & - & 0.0019 & 0.0040 & 0.0051 & 0.0072 & 0.0088 & 0.0125 \\
\hline & CA1 & $0.0048-0.0058$ & $0.0010-0.0019$ & $0.0025-0.0037$ & $0.0015-0.0023$ & - & 0.0039 & 0.0051 & 0.0070 & 0.0099 & 0.0128 \\
\hline & WI1 & $0.0056-0.0065$ & $0.0012-0.0018$ & $0.0040-0.0052$ & $0.0037-0.0043$ & $0.0035-0.0044$ & - & 0.0010 & 0.0029 & 0.0100 & 0.0082 \\
\hline & PA1 & $0.0058-0.0065$ & $0.0021-0.0027$ & $0.0046-0.0056$ & $0.0048-0.0054$ & $0.0047-0.0057$ & $0.0006-0.0012$ & - & 0.0027 & 0.0103 & 0.0076 \\
\hline & VA1 & $0.0082-0.0090$ & $0.0043-0.0048$ & $0.0068-0.0079$ & $0.0069-0.0075$ & $0.0065-0.0074$ & $0.0025-0.0032$ & $0.0025-0.0030$ & - & 0.0127 & 0.0093 \\
\hline \multirow[t]{2}{*}{ Resident } & TX1 & $0.0091-0.0102$ & $0.0074-0.0083$ & $0.0070-0.0082$ & $0.0083-0.0092$ & $0.0092-0.0106$ & $0.0094-0.0105$ & $0.0099-0.0108$ & $0.0121-0.0132$ & - & 0.0162 \\
\hline & FL1 & $0.0120-0.0129$ & $0.0099-0.0106$ & $0.0105-0.0116$ & $0.0121-0.0129$ & $0.0122-0.0134$ & $0.0076-0.0088$ & $0.0072-0.0081$ & $0.0089-0.0098$ & $0.0156-0.0168$ & - \\
\hline
\end{tabular}

\begin{tabular}{|l|l|}
\hline \multicolumn{2}{|c|}{ Key } \\
\hline & FST $<0.005$ \\
\hline & $0.005 \leq$ FST $<0.01$ \\
\hline & $0.01 \leq$ FST $<0.015$ \\
\hline & FST $\geq 0.015$ \\
\hline
\end{tabular}



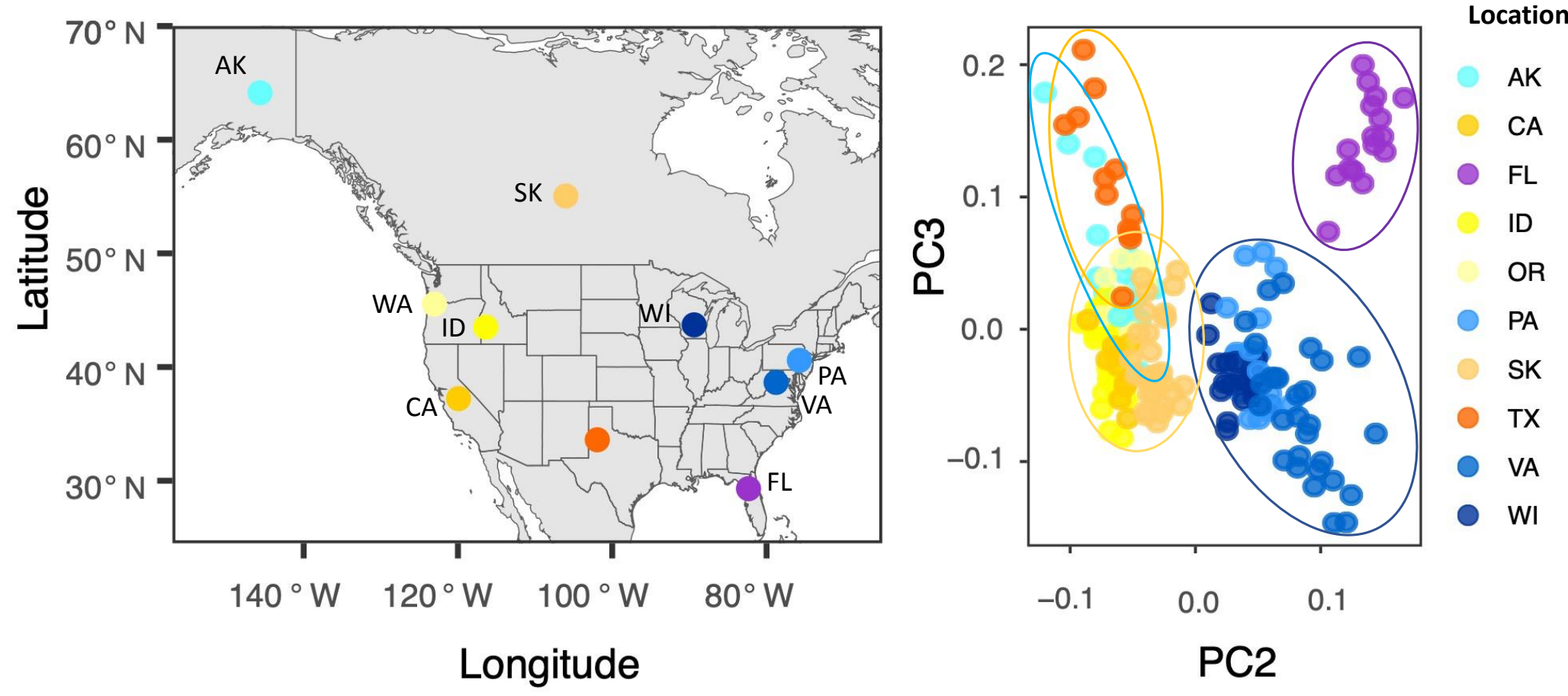

Figure 1. Principal components analysis of 72,263 Single Nucleotide Polymorphism markers from across the US and Canadian breeding range of American Kestrels showing separation among Eastern, Western, Alaska, and Texas genetically distinct populations, and the Florida subspecies. Each genetically distinct population is encircled by an ellipse. Separation between Alaska and Texas conservation units occurred along Principle Components axes not shown and was also evident in pairwise $\mathrm{F}_{\mathrm{ST}}$ calculations. 


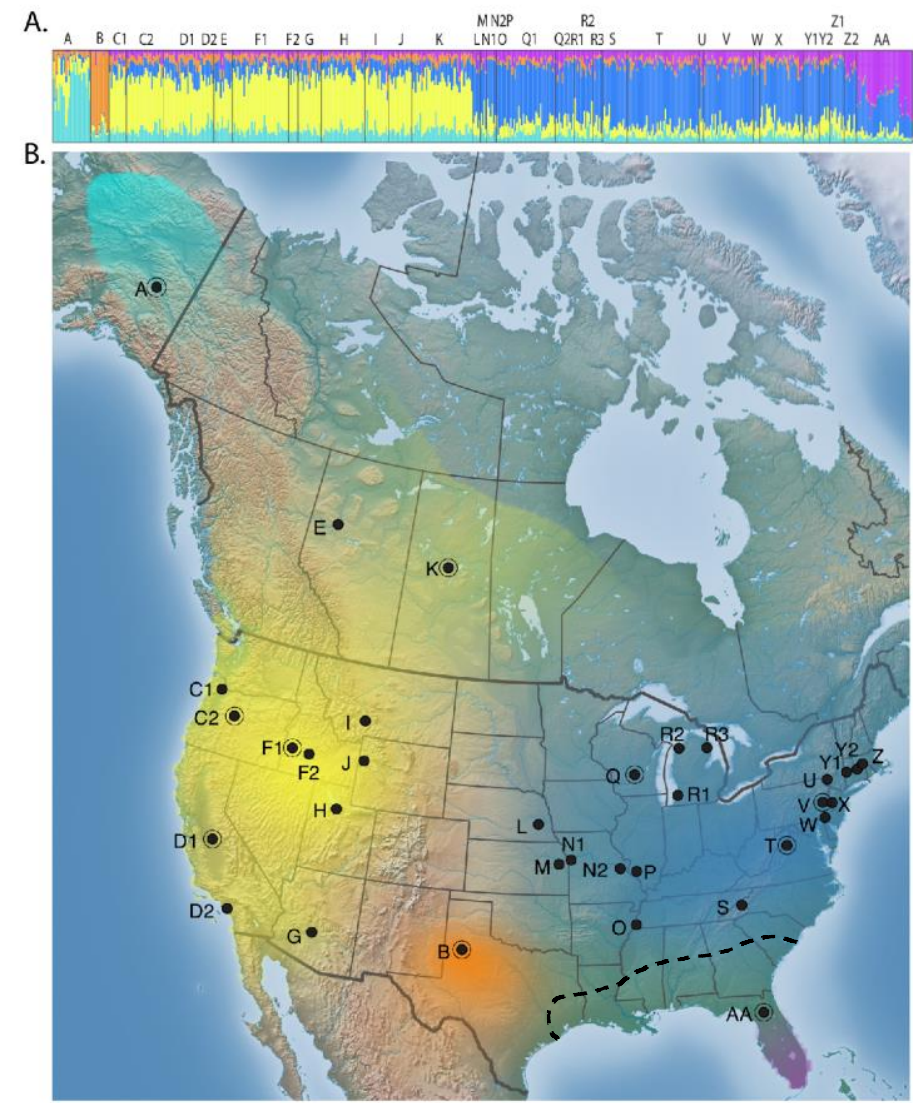

Figure 2. The American Kestrel genoscape. A) Structure plot showing support for $K=5$ genetic groups. Letters correspond to population locations on the map as well as sample numbers listed in Table 1. B) A spatially explicit representation of the population structure results showing the biggest genetic differences among eastern, western, Texas, Florida and Alaska genetic groups. Dots with circles around them indicate sampling locations where both Restriction-site associated-DNA sequencing and Single Nucleotide Polymorphism genotyping was conducted. The dashed line indicates the hypothesized southern boundary of $F$. S. sparvarius (Lane \& Fischer 1997). 


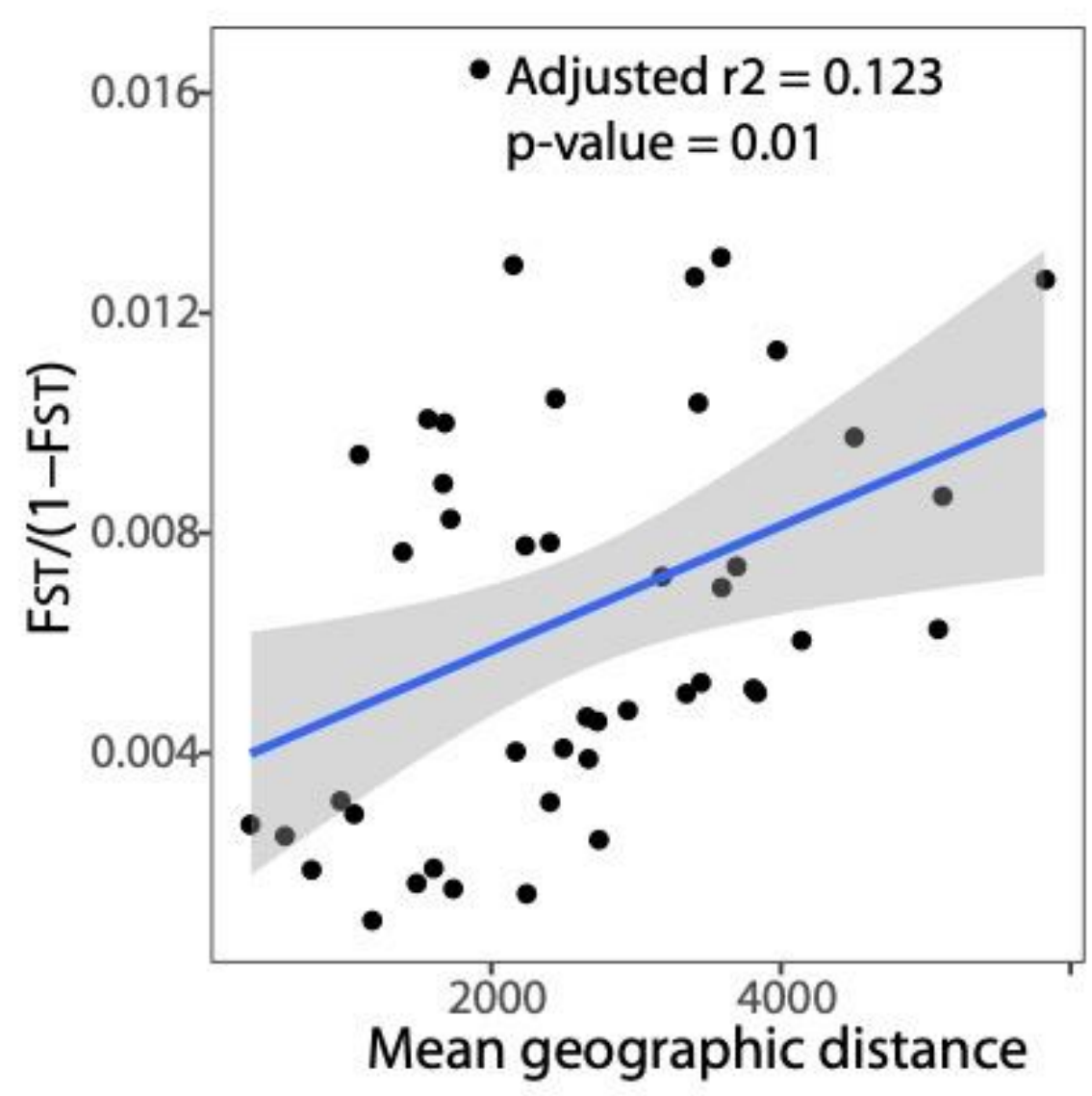

Figure 3. The relationship between pairwise linearized $F_{S T}$ and geographic distance for American Kestrel based on analysis of Restriction-Site-Associated DNA sequencing data. The significant $r^{2}$ supports the idea that genetic divergence across the range is largely a result of Isolation-by-Distance. 


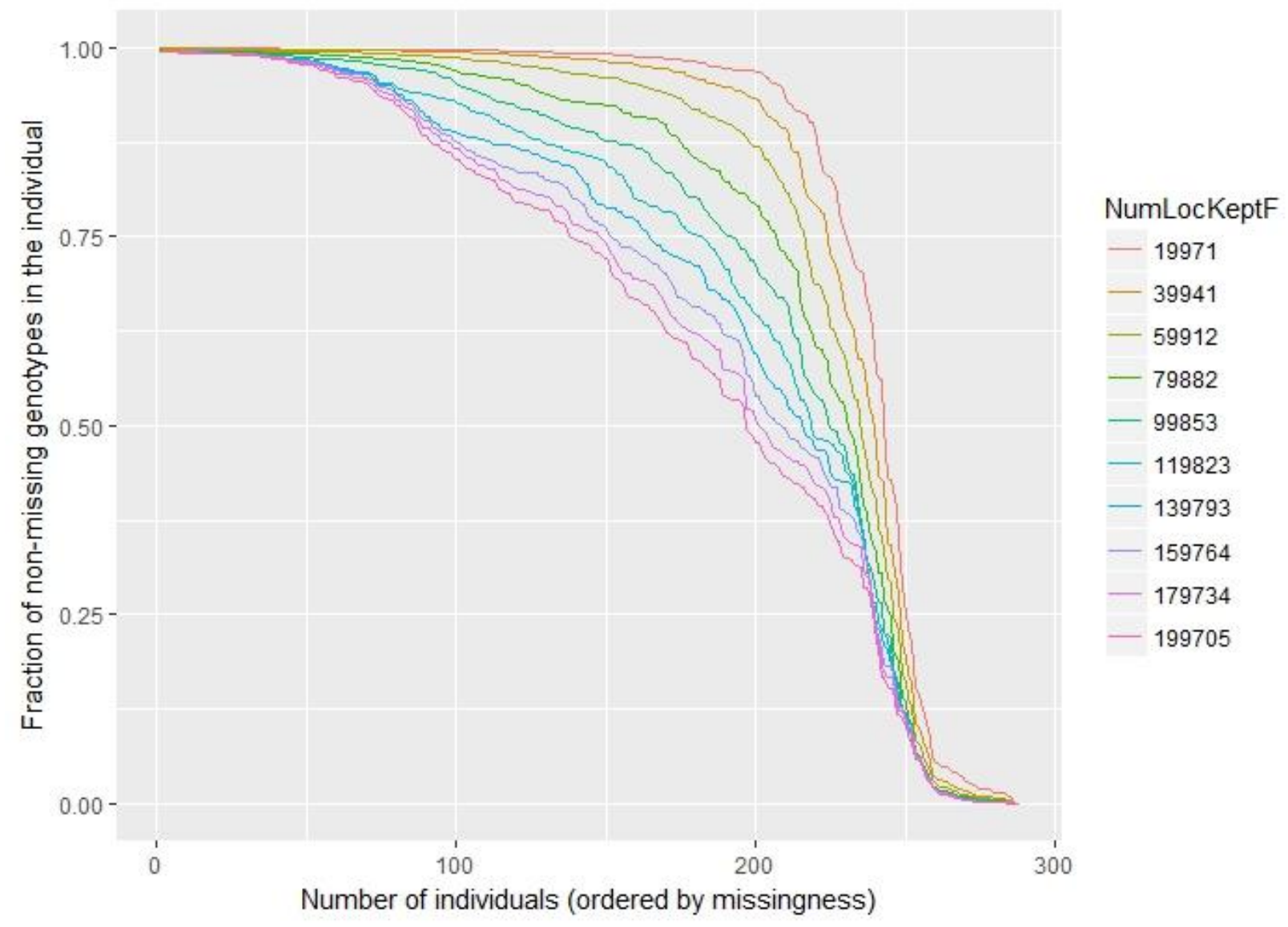

Figure SI 1. Missingness data per individual and per locus. We determined the final number of single nucleotide polymorphisms and individuals to be retained in analyses of population genetic structure of American Kestrels by visualizing the tradeoff between discarding low coverage single nucleotide polymorphisms ( $y$-axis) and individuals with missing genotypes (x-axis). Based on this analysis, we retained 75,000 SNPs and 204 individuals for further filtering using percent heterozygosity per individual and per locus. 


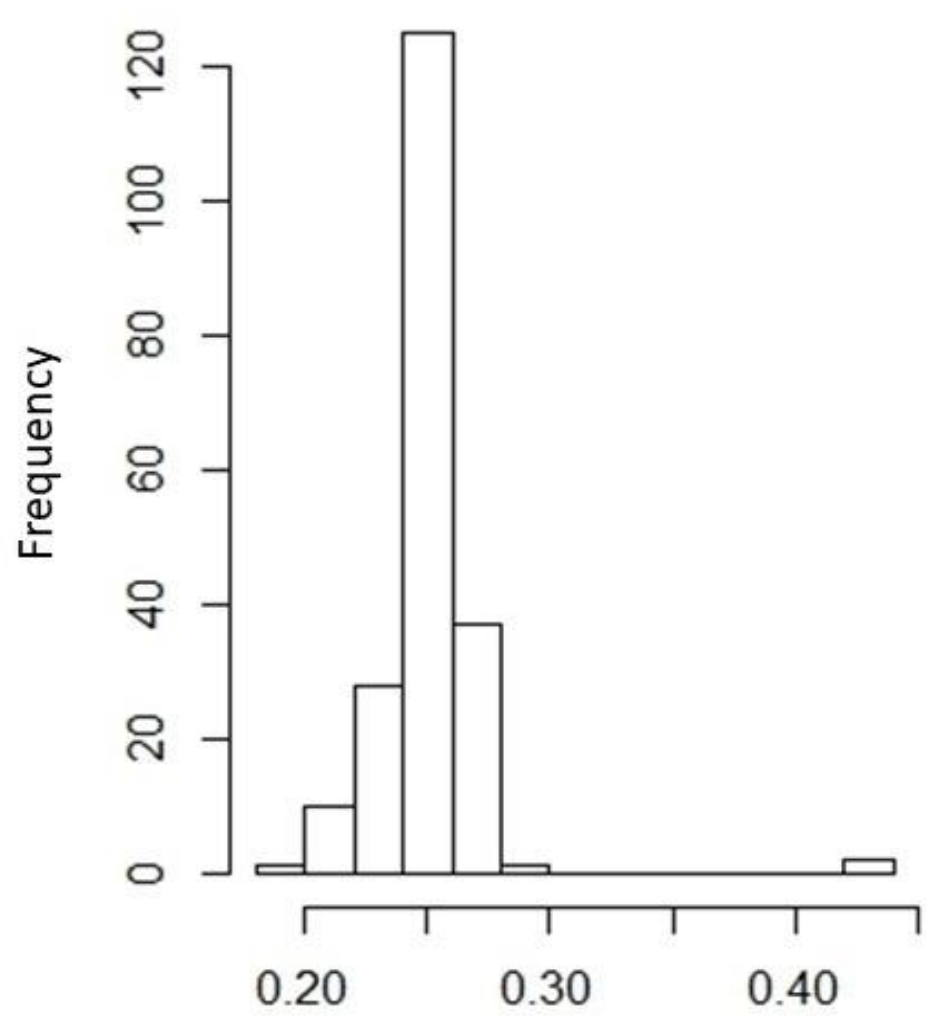

\section{Percent heterozygosity per individual}

Figure SI 2. Histogram of heterozygosity per individual. The above plot was used to identify high heterozygosity outliers above 0.40 which we subsequently removed from the analysis due to suspected contamination of samples. 
SI Figure 3. Population Structure in i American Kestrels assuming different numbers of populations. Ancestry plots generated in structure corresponding to $\mathrm{K}$ values of $2-6$, illustrating support for 5 genetically distinct lineages within American Kestrels. The sampling locations along the

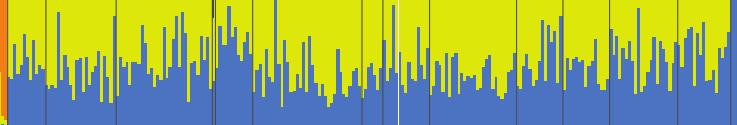
top bar correspond to the locations

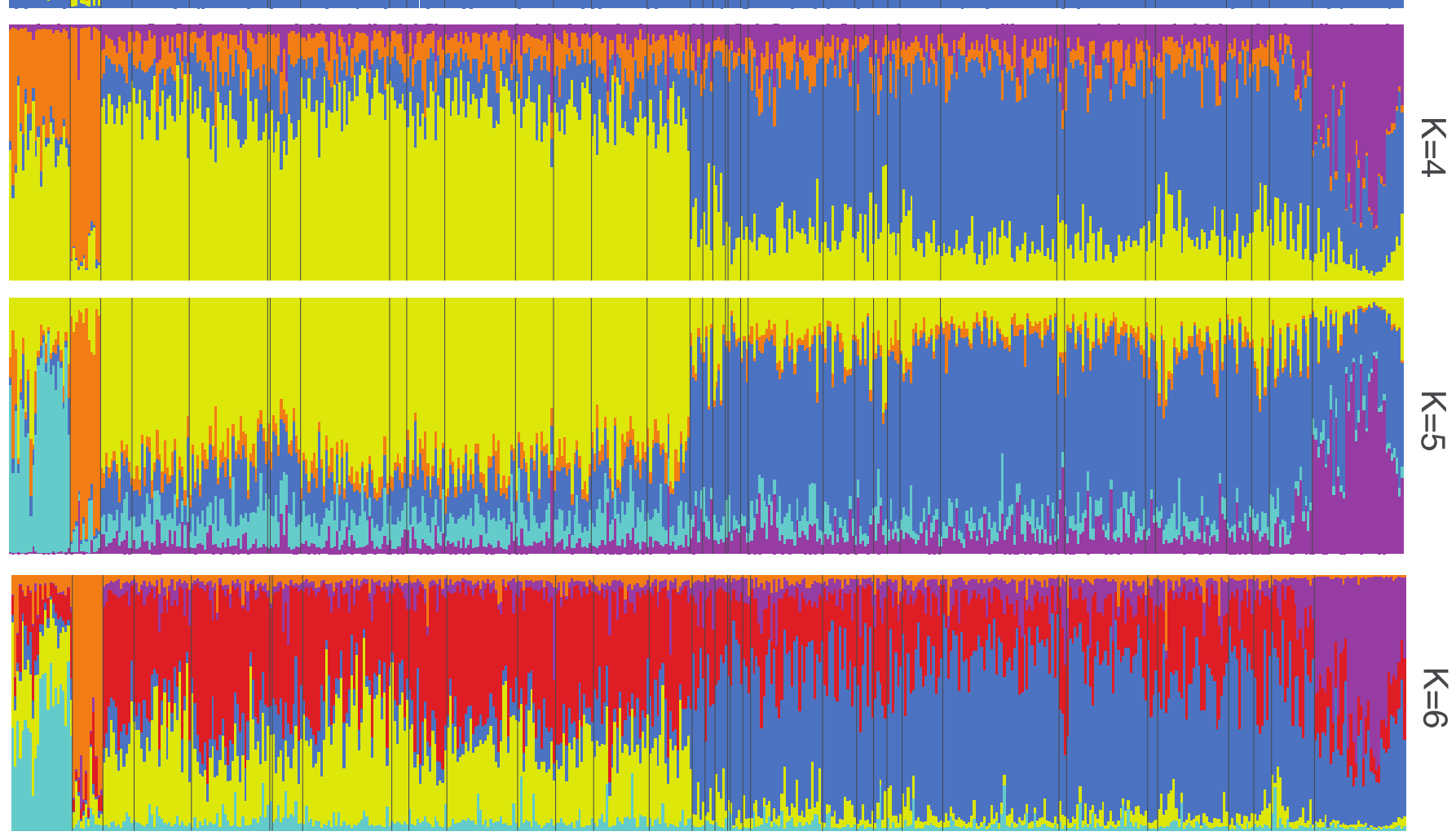
illustrated in Figure 2 and Table 1. 
A.

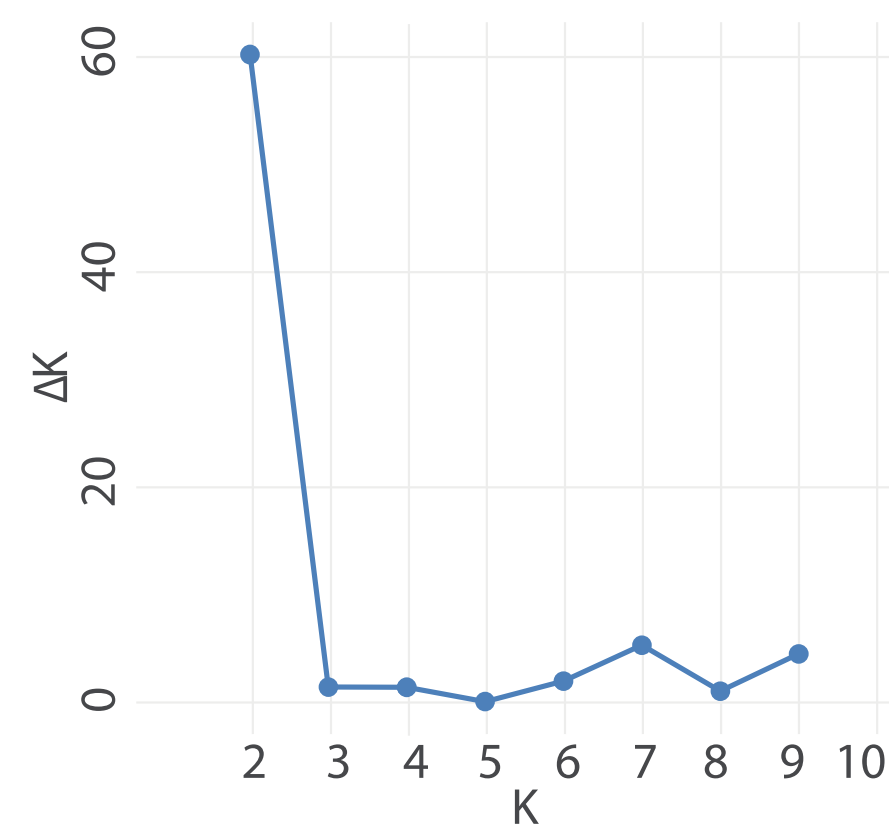

B.

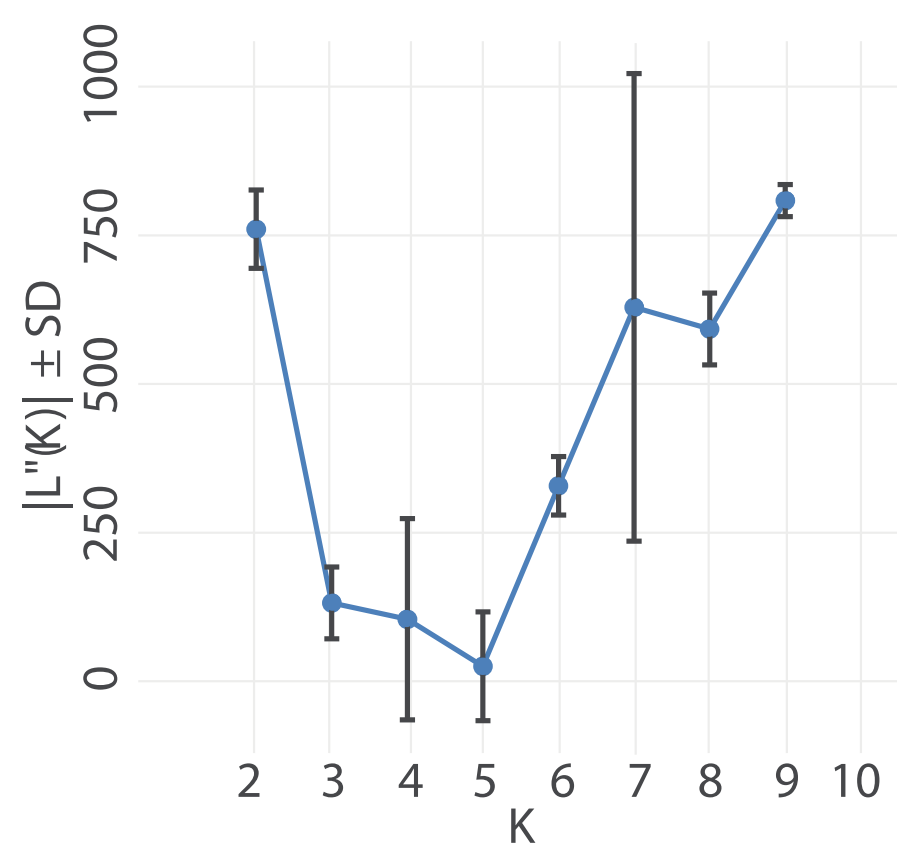

SI Figure 4. The Evanno method for determining the appropriate number of genetic clusters within the data (K). A) The change in $\mathrm{K}$ versus the number of clusters demonstrates $\mathrm{K}=3$ is the uppermost structure in the data. B) Visual inspection of the log likelihood values illustrate that $\mathrm{K}=5$ represents the best likelihood that is also a biologically reasonable value of $K$ for the number of populations within the American Kestrel data. 


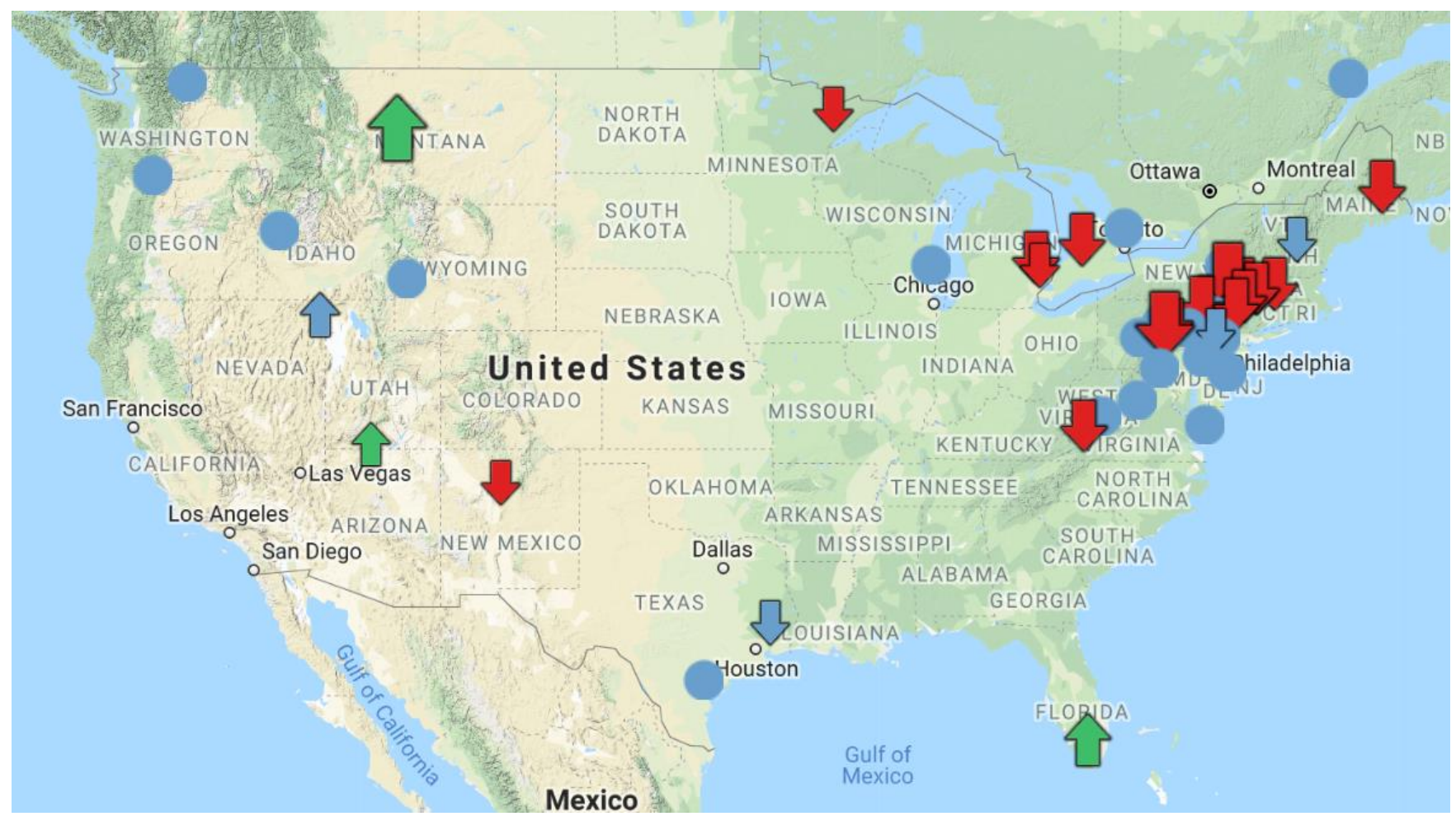

Figure SI 5. Population trends for American Kestrels from Raptor Population Index. A summary of population trend estimates based on migration count data from the Raptor Population Index (RPI) project (Crewe et al. 2016; Brandes et al. 2016). Green arrows represent areas of significant increase, blue arrows represent areas of slight increase (pointing up) or decrease (pointing down), red arrows represent areas of significant decrease, and blue circles signify areas with stable population trends. These data demonstrate the variability of population trend estimates of American Kestrels in North America, with the greatest declines occurring in the east. No trends are available for Alaska or Canada. 